\title{
A Cross-Sectional Study Exploring Motivators and Barriers to Physical Activity Participation Among Hospital Workers
}

\author{
Abdulla Saeed Al-Mohannadi ${ }^{1}$, Abdulla M. Albuflasa ${ }^{2}$, Suzan Sayegh ${ }^{1}$, Ahmad Salman $^{3}$ \& Abdulaziz Farooq ${ }^{1}$ \\ ${ }^{1}$ Research and Scientific Support Department, Aspetar Orthopaedic and Sports Medicine Hospital, Qatar \\ ${ }^{2}$ Education Department, Aspetar Orthopaedic and Sports Medicine Hospital, Qatar \\ ${ }^{3}$ College of Health Sciences, QU Health, Qatar University, Qatar \\ Correspondence: Abdulla Saeed Al-Mohannadi, Research and Scientific Support Department, Aspetar \\ Orthopaedic and Sports Medicine Hospital, Qatar. Tel: 97-45-551-5690. E-mail: \\ Abdulla.almohannadi@aspetar.com
}

Received: April 26, 2020 Accepted: June 1, 2020 Online Published: July 13, 2020

doi:10.5539/gjhs.v12n9p76 URL: https://doi.org/10.5539/gjhs.v12n9p76

\begin{abstract}
The workplace is an ideal setting to implement an effective health-promoting program. Insufficient information exists regarding the motivators and barriers to physical activity among working adults in Qatar. Therefore, this study aimed to identify the motivators and barriers to physical activity among adults in a healthcare setting. This cross-sectional study was conducted in an orthopaedic and sports medicine hospital. The participants were Qatari and non-Qatari adult staff $(n=100)$, who were recruited by word of mouth. They filled out self-administered questionnaires consisting of questions on age, gender, nationality, medical conditions, and the motivators (external, health/medical, and engagement) and barriers (personal, perceptual, and time constraint) to participating in physical activity. The characteristics of participants were: Age ( $<35$ years, $50.5 \%$; $\geq 35$ years, $49.5 \%)$, Gender (men, 47.5\%; women, 52.5\%), Nationality (Qatari, 51\%; non-Qatari, 49\%), and health status (healthy, $53 \%$; $\geq 1$ medical condition, $47 \%$ ). Common motivators particularly among workers $<35$ years, were the desire to maintain weight/shape (83.5\%), participating in a sport (67.7\%), and getting out of the house (64.2\%). Common barriers to exercise were weather $(84.9 \%)$ and family responsibilities $(84.4 \%)$. Other barriers, particularly among women, were difficulty in maintaining a routine $(82.1 \%)$ and finding physical activity uninteresting $(52.7 \%)$. The most common motivator to physical activity was the desire to maintain weight/shape and the main perceived barrier was the usual hot weather conditions most part of the year). Employers may need to consider the influence of these and other factors to improve the success of a physical activity program implemented in a workplace.
\end{abstract}

Keywords: barriers, motivators, physical activity, Middle East, hospital staff

\section{Introduction}

Physical inactivity is the fourth leading risk factor for death and contributes to $6 \%$ of deaths globally (World Health Organization, 2017b). The low prevalence of physical activity and poor nutrition have contributed to a rise in obesity and associated chronic diseases (e.g., metabolic syndrome, diabetes, cardiovascular disease) in Qatar, as well as globally (Ismail, 2012; Lee, Shiroma, \& Lobelo, 2012; Ng, Zaghloul, \& Ali, 2011; Salman, Sellami, et al., 2019; World Health Organization, 2006, 2017b). The consequences of physical inactivity create a disease burden in societies. Increasing physical activity (i.e., any movement of the skeletal muscles that causes energy expenditure could help to counter obesity and associated diseases (World Health Organization, 2017b). More than 45\% of adults in the State of Qatar do not meet the physical activity recommendations. It is well established that physical activity has many benefits on individuals' physical and psychological health, specifically in improving the overall well-being and quality of life, and decreasing the risk of developing lifestyle-related chronic diseases (Aspetar, 2014; Salman, Ukwaja et al., 2019; Salman \& Sellami, 2019; World Health Organization, 2008, 2017a). Evidence suggests that the increased sedentary behavior is due to the technological advances and environmental changes where prolonged daily sitting time has become a norm within office, home, and transport (Bauman et al., 2011; Thorp, Owen, \& Neuhaus, 2011).

The impact of physical inactivity in the workplace is not limited to healthcare costs; it moreover contributes to greater use of sick days due to musculoskeletal problems such as back pain (most common reason for sick leaves); 
depression; or other health conditions (e.g., diabetes); and can contribute to increased worker turnover because of absenteeism, early retirement, and disability (Proper, van den Heuvel, \& De Vroome, 2006). Individuals spend around one-third of their daytime at work, therefore, the implementation of physical activity interventions at a workplace setting can help in the reduction of prolonged sitting time and prevention of consequent diseases (Chapman, 2003; Mansi, Milosavljevic, \& Tumilty, 2015; Proper, van den Heuvel, \& De Vroome, 2006). The commonly known barriers to physical activity at the workplace setting include workload and lack of time, lack of knowledge, poor self-efficacy, lack of social support and self-motivation (Trost S G, Owen N, Bauman A E, Sallis $\mathrm{J} \mathrm{F}, 2002$ ). On the other hand, physical activity motivators can include social interaction, entertainment, incentives, health benefits awareness, role models, policies and regulations (Jepson et al., 2012).

The health benefits of physical inactivity are well-recognized; however, identifying the enabling and impeding factors to physical activity participation is a critical step to achieving sustained behavioral change and reduced risk of chronic diseases. More information is needed regarding motivators and barriers to increasing the levels of physical activity in the workplace setting in Qatar. Therefore, the aim of this study was to explore the motivators and barriers for physical activity participation among hospital workers in Qatar.

\section{Method}

\subsection{Study Design and Participants}

This cross-sectional study was conducted within a hospital setting in Qatar (Aspetar, Orthopedic and Sports Medicine Hospital [Doha, Qatar]). A total of 100 participants were -randomly selected from a hospital by using a convenient sampling technique and by word of mouth. The questionnaire was printed and distributed within clinical and non-clinical departments and participants were encouraged to complete the questionnaire by themselves. The inclusion criteria were adult ( $\geq 18$ years old) male and female workers. The exclusion criteria were visitors or patients. One hundred individuals ultimately completed and returned the questionnaires to the institution. (i.e., a return rate of $66.7 \%$ ). These individuals were therefore enrolled in the study.

The hospital setting included in this study provides various opportunities for physical activity through events, pedometer-based walk for health competitions and free membership access to fitness classes after work. One-hour break is provided to all. The working hours are from 8AM to 4PM with a 1-hour lunch break and staff are free to make choices on how to spend it.

\subsection{Data Collection}

A questionnaire was developed specifically for this study to collect data quantitatively. Most of the questions were therefore close-ended. There were series of questions related to barriers and motivators for physical activity. The survey instrument was used to identify motivators and barriers for physical activity among adults. The outcome measures were self-reported motivation and barriers to participating in physical activity. It is a self-administered questionnairewhich was developed based on previous literature and adapted for more consistency with local cultural context. The questionnaire was tested for reliability and internal consistency with a pilot sample of 20 subjects using a test and retest method. Subjects in the pilot study were included in the main study since the survey showed very good reliability. It was developed in English then translated into Arabic. The Arabic version of the questionnaire was back-translated into English to ensure the wording used in English corresponded with cultural context in Arabic and standards used within this population. The questionnaire included questions about basic demographic information (e.g., age, gender, nationality, presence of any medical condition) and motivations and barriers to participating in physical activity. No personal identifiable information was collected. The motivations and barriers were each subdivided into three subcategories. Barriers subcategories were personal, perceptual, and time constraint. Motivation subcategories were external, health/medical, and engagement.

\subsection{Ethical Considerations}

This research was approved by the Qatar Anti-Doping Lab Ethics Committee (SCH-ADL- E2017000215) and conformed to the recommendations of the Declaration of Helsinki.". All individuals provided written informed consent before participating in the study.

\subsection{Statistical Data Analysis}

Analyses were conducted using IBM Statistical Package for Social Sciences (SPSS) software statistics version 25 (IBM Corp, Armonk, New York, USA). All continuous data are presented as the mean \pm the standard deviation. Categorical data are presented as counts and percentages (\%). Any differences in categorical variables such as gender, age group and nationality were analyzed using Chi-square test of independence. A p-value $<0.05$ was considered as cut-off for statistical significance. 


\section{Results}

The characteristics of the participants are listed in Table 1. The number of individuals in each group were nearly equal with regard to age ( $\leq 35$ years $50.5 \%$ and $>35$ years $49.5 \%$ ), gender (women, $53 \%$; men, $47 \%$ ), nationality (Qatari, 51\%; non-Qatari, 49\%), and medical condition (no medical condition [i.e., healthy], 53\%; one or more conditions, $47 \%$ [ $27 \%$ had one medical condition and $20 \%$ had two or more medical conditions]).

Table 1. Characteristics of the population $(n=100)$

\begin{tabular}{lll}
\hline Variable & Valid frequency & Percentage \\
\hline Age group* & 49 & $50.5 \%$ \\
$\leq 35$ y & 48 & $49.5 \%$ \\
$>35$ y & & \\
\hline Sex* & 47 & $47.5 \%$ \\
Men & 52 & $52.5 \%$ \\
Women & & \\
\hline Nationality & 51 & $51 \%$ \\
Qatari & 49 & $49 \%$ \\
Non-Qatari & & \\
\hline No. of medical conditions & 53 & $53 \%$ \\
None & 27 & $27 \%$ \\
One & 20 & $20 \%$ \\
Two or more & & \\
\hline
\end{tabular}

* Missing data.

Figure 1 presents the external, health-medical, and engagement factors that motivate people to participate in physical activity. The most common motivating factor was the desire to maintain weight and shape $(83.5 \%)$, and the second and third most common motivating factors were to reduce weight $(80.0 \%)$ and to relieve stress $(78.3 \%)$, respectively. 


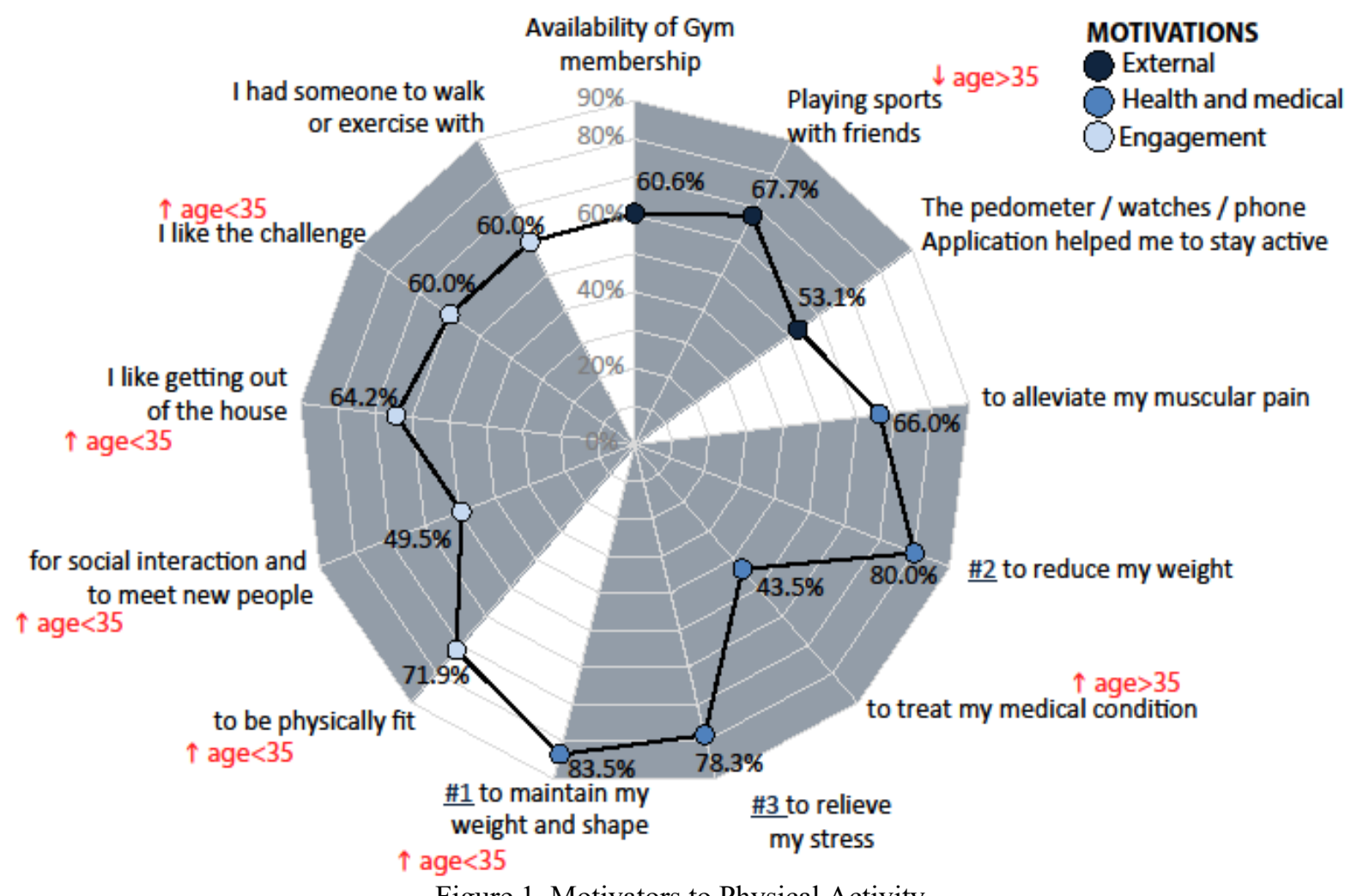

Regarding each motivating factor category, the three most common external motivating factors were playing sports with friends $(67.7 \%)$, the availability of a gym membership $(60.6 \%)$, and use of a pedometer through which a person kept track of the number of steps walked daily as a measure of activity level (53.1\%). The three most common health-medical motivating factors were to maintain weight and shape $(83.5 \%)$, reduce weight $(80.0 \%)$, and relieve stress (78.3\%). To a lesser extent, participants were motivated to engage in physical activity to alleviate muscle pain $(66.0 \%)$ or treat a medical condition $(43.5 \%$; more often reported by older participants). The three most common engagement motivating factors were to be physically fit $(71.9 \%)$, get out the house $(64.2 \%)$, and liking the challenge of performing an activity $(60.0 \%)$. The latter two factors were more often reported by younger participants. To a lesser extent, participants were motivated by having someone to walk/exercise with $(60 \%)$ or (for younger participants) using exercise (i.e., planned physical activity) to meet new people or for social interaction. The Chi-square analysis revealed that participants motivations for physical activity differed by age group. Subjects who were $>35$ years were more likely to be motivated in order to treat medical condition $(p=0.046)$, and play sports with friends ( $\mathrm{p}=0.002$ ). Whereas, most of the motivators for participants $<=35$ years were to maintain weight and shape $(\mathrm{p}=0.006)$, to be physically fit $(\mathrm{p}=0.001)$, for the challenge $(\mathrm{p}=0.011)$, for social interactions and meeting new people $(\mathrm{p}=0.035)$.

Figure 2 presents the personal, perceptual, and time constraint barriers to participating in physical activity. The most common barrier to exercise (i.e., personal, perceptual, and time constraint barriers combined) was weather (i.e., too hot/dusty/humid; $84.9 \%$ ). The second and third most common barriers were family responsibilities $(84.4 \%)$, and difficulty in maintaining a routine $(82.1 \%)$. 


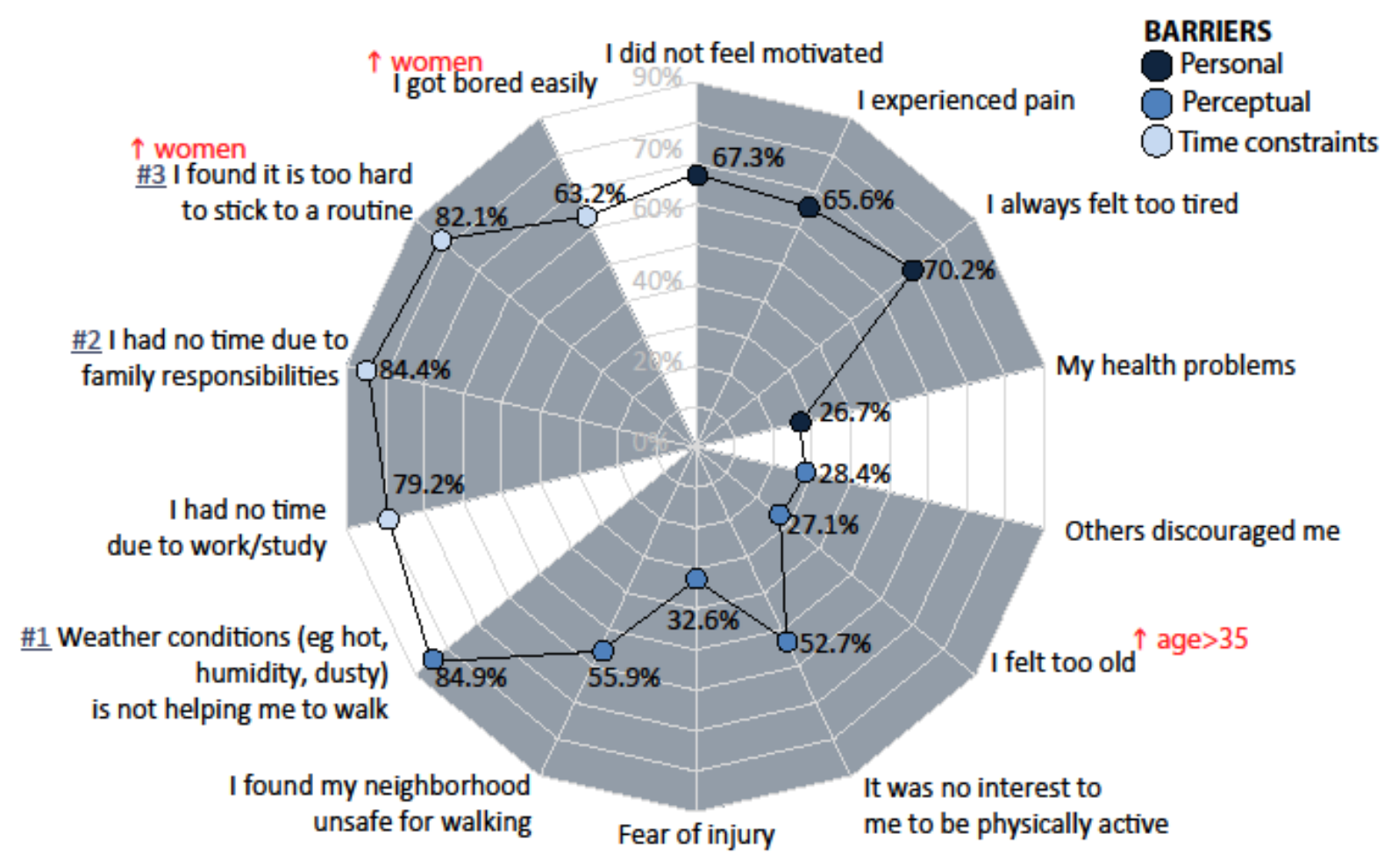

Figure 2. Barriers to Physical Activity

Regarding each barrier category, the three most common personal barriers were feeling too tired (70.2\%), feeling unmotivated $(67.3 \%)$, and pain (65.6\%). To a lesser extent, participants reported other health problems as a barrier (26.7\%). The three most common perceptual barriers were weather (84.9\%), belief that the neighborhood was too unsafe for walking $(55.9 \%)$ and finding the physical activity boring $(52.7 \%)$. Other perceptual barriers the participants reported were the fear that exercise would cause injury $(32.6 \%)$, others discouraged the participant from being more physically active (28.4\%), and (for older participants) feeling "too old" to exercise $(27.1 \%)$. The three most common time constraint barriers were family responsibilities $(84.4 \%)$, difficulty maintaining a routine (82.1\%), and lack of time because of work or study (79.2\%). Both barriers feeling bored easily and difficulty to maintain a routine were significantly higher in women $(\mathrm{p}=0.038)$.

\section{Discussion}

The results of this study indicate that in a cohort of hospital workers in Qatar, the main motivators for physical activity participation were to maintain weight and shape, reduce weight, or relieve stress. However, these motivating factors tended to be reported by younger adults $(<35$ years old). For adults older than 35 years, a motivating factor was to treat a health-medical condition. Young adults (i.e., $\leq 35$ years old) tended to report participating in physical activity to socialize or to get out of the house. On the other hand, the main barriers to increasing physical activity were weather conditions, social commitments, and, particularly for women, difficulty in maintaining a routine. Other barriers were health problems, social factors (e.g., feeling "too old", societal discouragement of women exercising), neighborhood unsafe for walking, pain, feeling bored or unmotivated to exercise, feeling tired, and lack of time because of work or study.

Encouraging women workers to become more physically active may be more challenging because women tend to be less active than men in middle eastern countries (Haj Bakri, 2013; Sayegh \& Van Der Walt, 2016). Barriers unique to women in this region such as clothing and societal norms can contribute to reduced activity. For example, in this region, the abaya (a common clothing item) can hinder movement and thereby prevent a woman from participating in moderate or vigorous activity. High-heeled shoes are uncomfortable for activities such as running and the noise from heeled shoes may be embarrassing and cause a woman to be less willing to walk (e.g., for fear the noise will annoy coworkers). Other investigators have similarly noted the barrier presented by clothing, as well as other barriers among Gulf women such as an unwillingness to sweat; an unwillingness to wear certain types of clothing that could ease their participation in a sport-like activity, even in women-only settings; the concern that 
makeup and other grooming efforts will be ruined by exercising; the difficulty in having someone drive them to a setting (e.g., gym) where they can participate in an activity; and discouragement by family from participation in physical activity (Berger \& Peerson, 2009).

Increasing the activity level of obese workers may be problematic because obesity reduces a person's activity level (Ekelund \& Brage, 2008; Godin \& Belanger-Gravel, 2008; Levine, McCrady, \& Lanningham-Foster, 2008; Pedisic, Grunseit, \& Ding, 2014; Petersen \& Schnohr, 2004), and obese people tend to drop out of exercise programs (Ekkekakis, Vazou, \& Bixby, 2016). Some investigators have reported that a very low percentage (nearly $0 \%$ ) of overweight and obese people adhere to the recommended guidelines of attaining at least 60 minutes/day of moderate to vigorous activity to prevent weight gain, or 60-90 minutes/day of moderate activity to maintain weight loss (Ekkekakis, Vazou, \& Bixby, 2016; Fogelholm, Kukkonen-Harjula, \& Nenonen, 2000). In this study however, unfortunately BMI was not recorded, therefore we are unable to comment on the common barriers or motivators to physical activity in this population.

The primary barrier to being more physically active reported by people is insufficient time (Ekkekakis, Vazou, \& Bixby, 2016). Based on this complaint, a program that involves vigorous exercise for a short duration (e.g., 30 minutes/day) would increase adherence to a program. However, no empirical evidence supports that high intensity exercise of short duration enhances adherence to an exercise program (Ekkekakis, Vazou, \& Bixby, 2016).

Facilitating the participation of workers in physical activity programs may be accomplished by making exercise more pleasurable and by incorporating behavioral interventions (De Feo, 2013; Fogelholm, Kukkonen-Harjula, \& Nenonen, 2000; Jeffery, Wing, \& Sherwood, 2003). Fogelholm et al. indicated that women could use different exercise strategies as long as they met their energy-expenditure goals to control body mass (Fogelholm, Kukkonen-Harjula, \& Nenonen, 2000). The women in this study tended to prefer lower intensity of exercise, although it increased the total exercise time to achieve the energy expenditure required to maintain body mass (i.e., the lower intensity exercise was more comfortable). Jeffery et al. reported a dropout rate of $20 \%$ among individuals participating in an exercise program for 18 months (Jeffery, Wing, \& Sherwood, 2003). The participants could invite family and friends to participate in the program; they received individualized attention from exercise coaches for emotional support, problem-solving strategies, and progress assessment; and they received monetary rewards for achieving or exceeding their energy-expenditure goals. Church et al. achieved a dropout rate of less than $9 \%$ over 6 months among women by using financial incentives, behavioral contracts, and individualized support from staff (Church, Earnest, \& Skinner, 2007).

The workplace is an appropriate setting to institute health-promoting programs for several reasons: workers spend a substantial amount of time at work, physical activity can improve a person's mood and therefore worker morale, and positive peer pressure by coworkers can help a worker establish or maintain good health habits. In addition, instituting health-promoting activities among workers is beneficial for the workplace in that such programs have been shown to reduce costs associated with workers' use of health care, sick leave, and loss of the workforce due to workers taking early retirement because of health-related factors. For example, Chapman (Chapman, 2003) in a meta-analysis of 42 studies, examined the economic effects of workplace health-promotion programs implemented among a wide range of industries. The meta-analysis revealed a mean reduction of $28.3 \%$ in sick leave/absenteeism; $26.1 \%$ in health costs, and $30.1 \%$ in the cost for workers' compensation and disability management claims. Proper and colleagues (Proper, van den Heuvel, \& De Vroome, 2006) examined the extent that different levels of activity (i.e., moderate versus vigorous) impacted sick leave in the workplace, based on information from three large Dutch medical databases Proper et al.10 found no statistical difference in the mean sick leave duration between individuals participating in moderate activity and those who did not. However, all three databases showed that people who did not participate in vigorous physical activity had longer sick leave times, compared to people who participated in vigorous activity. The study also found that vigorous activity up to a frequency of three times weekly can reduce sick leave.

To encourage increased physical activity among employees, employers will have to take into consideration personal, perceptual, and time constraint barriers when implementing a health-promoting program. This study has identified the main barriers to target.

In Qatar, hot weather is a major barrier to physical activity and impacts the average number of steps adults take per day: as heat and humidity increase, the number of daily steps decreases (Al-Mohannadi, Farooq, \& Burnett, 2016). Promoting physical activity in indoor air-conditioned areas in a workplace can provide an alternative environment where workers could meet daily physical activity needs. Moreover, according to a recent study among healthcare workers in Qatar, participants' level of physical activity has increased during a walking intervention. Individuals are more motivated during physical activity programs (Al-Mohannadi et al., 2019). 
Having insufficient time to participate in physical activity because of one's work schedule was another common barrier among the population in this study. Education about the importance of physical activity and smart prioritizing of the time demands of work and life are needed in this population.

In general, people are aware of the health benefits associated with physical activity. However, a safe place to participate in physical activity is inaccessible for most people. Therefore, a common barrier was "not having a safe place to practice physical activity." Providing an area in the workplace where workers feel safe exercising or doing other physical activity could be an alternative to address this barrier.

Two-thirds of the participants complained they get bored easily with physical activity. This complaint was significantly higher in women. This finding indicates that perhaps physical activity is not emphasized as fun and enjoyable and the activity may not include social interaction. Some recommendations for this barrier are as follows: employers could provide opportunities that encourage workers to participate in local and national events such as sports-sponsored walks; occasionally offer "work-free" days (i.e., team-gathering opportunities that involve a physical activity that most staff members can participate in); provide corporate activity challenges with prizes; or ask employees for their input regarding which activities they would be interested participating in.

Another barrier that can exist among workers, especially among women, is that a worker may not be well-informed about the benefits of physical activity. For example, Berger and Peerson found that the women in their study had no education or vague ideas about the health benefits of physical activity (e.g., one participant stated: "I think that walking doesn't give that much benefit, but I don't know as we never got much information from school about health") (Berger \& Peerson, 2009). Because education can enhance changes in behavior, employers could provide educational programs that teach workers about the impact of exercise and physical activity on health.

Other ways employers can increase activity among workers is to develop an organization-wide policy that supports employees in being more physically active; encourage workers to walk, jog, or cycle to work (however, this approach would not be possible to implement in Qatar because of the lack of walking facilities and the environmental challenges for many months of the year and encourage workers to join a corporate membership with a local leisure service. Workers can personally implement simple measures to increase their activity level in the workplace. For example, a worker can use stairs rather than an elevator to increase activity or walk to an office rather than sitting and phoning the office. The hospital staff are in a good position to offer recommendations for physical activity to the patients and are the main source of information for patients. This study provides information on the barriers and motivators for physical activity among health care workers but it is limited to small sample size and restricted to one hospital in Qatar. To maintain anonymity data profession was not collected, hence it was not able to classify motivators and barriers between clinical and non-clinical staff. Being a sports medicine setting, it could be biased towards underestimating the population prevalence in other hospital settings in Qatar. Further studies are needed to sample other hospital institutions.

\section{Conclusions}

With the prevalence of obesity and associated health problems (e.g., diabetes, metabolic syndrome, cardiovascular disease) increasing in the Gulf Region (Aspetar, 2014; Ismail, 2012; Rahim, Sibai, \& Khader, 2014; World Health Organization, 2006), efforts to increase physical activity are needed. The workplace can be instrumental in helping workers to adopt healthy behaviors and increase their activity level. A greater awareness of common factors that motivate workers and barriers that prevent workers from obtaining enough physical activity can aid workplaces in implementing effective health-promoting programs.

\section{Implications for Policy and Practice}

- Workplace is an ideal location for physical activity promotion

- The barriers to physical activity identified in this study stresses the need for multilevel interventions that is not only structured at organization level but also at an individual level.

- It is important to remind health care staff regardless of clinical or non-clinical units that they are role models for patients who visit the institution. This may encourage healthy lifestyle behavior.

- Time constraints were a major barrier to physical activity among men and women in this study. Education interventions should focus on supporting individuals to identify small durations such as $30 \mathrm{~min}$ in their daily schedule and make achievable targets such as walking or jogging.

- Staff can integrate physical activity with work by frequently interrupting sedentary behavior through walking breaks, park away from the office, use of stairs, arrange walking meetings, etc.

- Increasing level of social support for older staff and creating opportunities for younger staff for internal 
workplace sports challenges can be considered.

- At the institution-level, lunch breaks could be re-identified as activity breaks and can be offered separated from meal time.

\section{Competing Interests Statement}

The authors declare that there are no competing or potential conflicts of interest.

\section{References}

Al-Mohannadi, A. S., Sayegh, S., Ibrahim, I., Salman, A., \& Farooq, A. (2019). Effect of a pedometer-based walking challenge on increasing physical activity levels amongst hospital workers. Archives of Public Health, 77(40), 1-8. https://doi.org/10.1186/s13690-019-0368-7

Al-Mohannadi, A. S., Farooq, A., Burnett, A., \& Al-Kuwari, M. G. (2016). Impact of climatic conditions on physical activity: a 2-year cohort study in the Arabian Gulf Region. Journal of Physical Activity and Health, 13, 929-937. https://doi.org/10.1123/jpah.2015-0593

Aspetar. (2014). Qatar National Physical Activity Guidelines. Aspetar, Orthopaedic and Sports Medicine Hospital. Retrieved from http://www.namat.qa/NamatImages/Publications/75/QATARPAGUIDLINEENGLISH.PDF

Bauman, A., Ainsworth, B. E., Sallis, J. F., Hagstromer, M., Craig, C. L., Bull, F. C., ... \& Sjostrom, M. (2011). The descriptive epidemiology of sitting. A 20-country comparison using the International Physical Activity Questionnaire (IPAQ). Am J Prev Med, 41(2), 228-235. https://doi.org/10.1016/j.amepre.2011.05.003

Berger, G., \& Peerson, A. (2009). Giving young Emirati women a voice: participatory action research on physical activity. Health and Place, 15, 117-124. https://doi.org/10.1016/j.healthplace.2008.03.003

Chapman, L. S. (2003). Meta evaluation of worksite health promotion economic return studies. Art of Health Promotion, 6, 1-16.

Church, T. S., Earnest, C. P., Skinner, J. S., \& Blair, S. N. (2007). Effects of different doses of physical activity on cardiorespiratory fitness among sedentary, overweight or obese postmenopausal women with elevated blood pressure: a randomized controlled trial. Jama, 297(19), 2081-2091. https://doi.org/10.1001/jama.297.19.2081

De Feo, P. (2013). Is high-intensity exercise better than moderate-intensity exercise for weight loss? Nutritoin, Metabolism, and Cardiovascular Diseases, 23, 1037-1042. https://doi.org/10.1016/j.numecd.2013.06.002

Ekelund, U., Brage, S., Besson, H., Sharp, S., \& Wareham, N. J. (2008). Time spent being sedentary and weight gain in healthy adults: reverse or bidirectional causality?. The American journal of clinical nutrition, 88(3), 612-617. https://doi.org/10.1093/ajcn/88.3.612

Ekkekakis, P., Vazou, S., Bixby, W. R., \& Georgiadis, E. (2016). The mysterious case of the public health guideline that is (almost) entirely ignored: call for a research agenda on the causes of the extreme avoidance of physical activity in obesity. Obesity Reviews, 17(4), 313-329. https://doi.org/10.1111/obr.12369

Fogelholm, M., Kukkonen-Harjula, K., Nenonen, A., \& Pasanen, M. (2000). Effects of walking training on weight maintenance after a very-low-energy diet in premenopausal obese women: a randomized controlled trial. Archives of Internal Medicine, 160(14), 2177-2184. https://doi.org/10.1001/archinte.160.14.2177

Godin, G., Bélanger-Gravel, A., \& Nolin, B. (2008). Mechanism by which BMI influences leisure-time physical activity behavior. Obesity, 16(6), 1314-1317. https://doi.org/10.1038/oby.2008.219

Haj Bakri A, A.-T. A. (2013). Qatar STEPwise Report 2012: Chronic Disease Risk Factor Surveillance. Supreme Council of Health.

Ismail, M. F. S. (2012). Metabolic syndrome among obese Qataris attening primary health care centers in Doha, 2010. Journal of Family and Community Medicine, 19, 7-11. https://doi.org/10.4103/2230-8229.94004

Jeffery, R. W., Wing, R. R., Sherwood, N. E., \& Tate, D. F. (2003). Physical activity and weight loss: does prescribing higher physical activity goals improve outcome?. The American journal of clinical nutrition, 78(4), 684-689. https://doi.org/10.1093/ajcn/78.4.684

Jepson, R., Harris, F. M., Bowes, A., Robertson, R., Avan, G., \& Sheikh, A. (2012). Physical activity in South Asians: an in-depth qualitative study to explore motivations and facilitators. PloS One, 7(10), e45333. https://doi.org/10.1371/journal.pone.0045333

Lee, I. M., Shiroma, E. J., Lobelo, F., Puska, P., Blair, S. N., Katzmarzyk, P. T., \& Lancet Physical Activity Series Working Group. (2012). Effect of physical inactivity on major non-communicable diseases worldwide: an 
analysis of burden of disease and life expectancy. The lancet, 380(9838), 219-229. https://doi.org/10.1016/S0140-6736(12)61031-9

Levine, J. A., McCrady, S. K., Lanningham-Foster, L. M., Kane, P. H., Foster, R. C., \& Manohar, C. U. (2008). The role of free-living daily walking in human weight gain and obesity. Diabetes, 57(3), 548-554. https://doi.org/10.2337/db07-0815

Mansi, S., Milosavljevic, S., Tumilty, S., Hendrick, P., Higgs, C., \& Baxter, D. G. (2015). Investigating the effect of a 3-month workplace-based pedometer-driven walking programme on health-related quality of life in meat processing workers: a feasibility study within a randomized controlled trial. BMC public health, 15(1), 1-12. https://doi.org/10.1186/s12889-015-1736-Z

Ng, S. W., Zaghloul, S., Ali, H. I., Harrison, G., \& Popkin, B. M. (2011). The prevalence and trends of overweight, obesity and nutrition-related non-communicable diseases in the Arabian Gulf States. Obesity Reviews, 12(1), 1-13. https://doi.org/10.1111/j.1467-789X.2010.00750.x

Pedisic, Z., Grunseit, A., Ding, D., Chau, J. Y., Banks, E., Stamatakis, E., ... \& Bauman, A. E. (2014). High sitting time or obesity: Which came first? Bidirectional association in a longitudinal study of 31,787 A ustralian adults. Obesity, 22(10), 2126-2130. https://doi.org/10.1002/oby.20817

Petersen, L., Schnohr, P., \& Sørensen, T. I. A. (2004). Longitudinal study of the long-term relation between physical activity and obesity in adults. International journal of obesity, 28(1), 105-112. https://doi.org/10.1038/sj.ijo.0802548

Proper, K. I., Van den Heuvel, S. G., De Vroome, E. M., Hildebrandt, V. H., \& Van der Beek, A. J. (2006). Doseresponse relation between physical activity and sick leave. British journal of sports medicine, 40(2), 173-178. https://doi.org/10.1136/bjsm.2005.022327

Rahim, H. F. A., Sibai, A., Khader, Y., Hwalla, N., Fadhil, I., Alsiyabi, H., ... \& Husseini, A. (2014). Non-communicable diseases in the Arab world. The Lancet, 383(9914), 356-367. https://doi.org/10.1016/S0140-6736(13)62383-1

Salman, A., \& Sellami, M. (2019). Do older adults with multimorbidity meet the recommended levels of physical activity? An analysis of Scottish health survey. International Journal of Environmental Research and Public Health, 16(19), 3748. https://doi.org/10.3390/ijerph16193748

Salman, A., Sellami, M., Al-Mohannadi, A. S., \& Chun, S. (2019). The associations between mental well-being and adherence to physical activity guidelines in patients with cardiovascular disease: Results from the scottish health survey. International Journal of Environmental Research and Public Health, 16(19), 3596. https://doi.org/10.3390/ijerph16193596

Salman, A., Ukwaja, K. N., \& Alkhatib, A. (2019). Factors Associated with Meeting Current Recommendation for Physical Activity in Scottish Adults with Diabetes. International Journal of Environmental Research and Public Health, 16(3857). https://doi.org/10.3390/ijerph16203857

Sayegh, S., Van Der Walt, M., \& Al-Kuwari, M. G. (2016). One-year assessment of physical activity level in adult Qatari females: a pedometer-based longitudinal study. International journal of women's health, 8, 287. https://doi.org/10.2147/IJWH.S99943

Thorp, A. A., Owen, N., Neuhaus, M., \& Dunstan, D. W. (2011). Sedentary behaviors and subsequent health outcomes in adults: a systematic review of longitudinal studies, 1996-2011. American journal of preventive medicine, 41(2), 207-215. https://doi.org/10.1016/j.amepre.2011.05.004

Trost, S. G., Owen, N., Bauman, A. E., Sallis, J. F., \& Brown, W. (2002). Correlates of adults' participation in physical activity: review and update. Medicine \& science in sports \& exercise, 34(12), 1996-2001. https://doi.org/10.1097/00005768-200212000-00020

World Health Organization. (2006). World Health Survey Qatar. World Health Organization.

World Health Organization. (2008). Preventing Noncommunicable Diseases in the Workplace through Diet and Physical Activity. World Health Organization.

World Health Organization. (2017a). Integrated care for older people: guidelines on community-level interventions to manage declines in intrinsic capacity.

World Health Organization. (2017b). Physical Activity. World Health Organization. 


\section{Copyrights}

Copyright for this article is retained by the author(s), with first publication rights granted to the journal.

This is an open-access article distributed under the terms and conditions of the Creative Commons Attribution license (http://creativecommons.org/licenses/by/4.0/). 